\title{
La cultura visual contemporánea y la cuestión de la materialidad. Imágenes, mediaciones, figuralidad 1
}

\section{Comtemporary visual culture and the question of materiality. Images, mediations, figurality}

\author{
Sergio Martínez LunA \\ Universidad Carlos III de Madrid/Universidad Camilo José Cela de Madrid \\ sergiomluna@hotmail.com
}

Recibido: 30-06-2015

Aceptado: 12-03-2016

\section{Resumen}

Las transformaciones contemporáneas de la imagen afectan a las formas de la memoria, el valor y el conocimiento. Las imágenes pueden considerarse como mediadoras de sí mismas. Estos cambios en la esfera de la visualidad se ligan frecuentemente a la idea de que las imágenes y la visualidad contemporáneas son inmateriales. El artículo señala la insuficiencia de esta aproximación por la que se vuelve a filtrar la lógica dualista de separación entre mente y cuerpo. La visualidad contemporánea implica nuevas relaciones entre lo material, lo visual y lo virtual. La materialidad de la imagen tiene que ver con dimensiones como la de figuralidad. Las dimensiones materiales de la imagen señalan la imposibilidad de reducir lo visual a lo lingüístico, lo textual o lo histórico, ámbitos a los que está ligada pero a los que a la vez desborda.

Palabras clave: imagen, visualidad, materialidad, mediación, figuralidad.

\footnotetext{
1 Este artículo ha sido financiado por el Ministerio de Economía y Competitividad (España) en el marco del Proyecto de investigación FFI2013-45659-R: Culturas materiales, culturas epistémicas, estándares, procesos cognitivos y conocimiento.
} 


\begin{abstract}
Contemporary transformations of image affect forms of memory, value, and knowledge. Images can be considered as mediations of themselves. These changes in the field of visuality are often linked to the idea that contemporary images and visuality are immaterial. The article points out the insufficiency of such an approach, whereby the dualistic logic that separates mind and body is reintroduced. Contemporary visuality implies new relations between the material, the visual, and the virtual. The materiality of image has to do with concepts such as the figurality. The material dimensions of image emphasize the impossibility of reducing the visual to the linguistic, textual, or historical. Image is linked to those areas but they are at the same time beyond their scope.
\end{abstract}

Keywords: image, visuality, materiality, mediation, figurality.

\title{
1. Introducción
}

La imagen contemporánea se está distanciando de sus obligaciones con la mímesis, la representación, la memoria y el sentido, proceso por el cual gana una dimensión ontológica, pero cuya novedad es relativa, pues las formas en que se desea o se teme la vida de las imágenes tienen una historia y están implicadas en una multitud de escenarios. Cabe, entonces, historizar ese estatus ganado por las imágenes en las sociedades actuales para entender el alcance de lo que se ha reconocido como un cambio de régimen escópico o un giro visual en su propia especificidad, de forma que tal reconocimiento no revierta en el emborronamiento de otras rupturas, de las características propias de otros regímenes. Es posible así proyectar las condiciones actuales de la visualidad sobre la historia cultural, las configuraciones epistémicas, la diferencia cultural o los repartos del valor ${ }^{2}$. A lo largo de esas relaciones emerge con especial fuerza la cuestión de la materialidad de las imágenes, en la medida en que la economía contemporánea de lo visual identifica a aquellas y a sus nuevas potencialidades con la imagen inmaterial, desmaterializada o virtual. El cambio de régimen escópico, el giro visual o "pictórico" parece, en un primer momento, ligado a la expansión cuantitativa de las imágenes en la cultura actual.

\footnotetext{
2 Este enfoque no es por supuesto completamente novedoso y, de hecho, se puede remontar por ejemplo a Wölfflin, que subrayaba que cada época percibe el mundo de diferentes maneras. Y así: "La capacidad de ver tiene también su historia, y el descubrimiento de estratos ópticos ha de considerarse como la tarea más elemental de la historia artística". Wölfflin, H., Conceptos fundamentales de la Historia del Arte, Madrid, Espasa, 2011, p. 33.
} 
Sin embargo, se ha de añadir a tal fenómeno cuantitativo el impacto de la imagen en la organización de los mundos de vida y en la economía del conocimiento. De acuerdo con José Luis Brea el devenir imagen del capitalismo contemporáneo -configurado a través del proceso de acumulación y transfiguración del mundo en la forma de la mercancía- compone una cierta deriva, cualitativa, del propio sistema capitalista. En éste ya no se trata de que las imágenes sean mediadoras de los objetos a los que reemplazarían, sino que las imágenes alcanzan una autonomía operativa, y de este modo "serían sus propios mediadores, ya no actuarían como sustitutos-sucedáneos sino acaso, y únicamente, de sí mismas"3. Esta fuerza constitutiva de las imágenes es resultado de una expansión cuantitativa que acaba revirtiendo en la intensificación de la dimensión performativa de lo visual, como productora de identidades y entidades sociales, exclusiones y subjetividades.

En cualquier caso, el llamado giro visual, al menos tal y como lo explicaba W.J.T. Mitchell, sería en todo caso un episodio más dentro de una larga pugna entre imágenes y palabras, en la que secularmente se viene jugando la primacía, la legitimidad o el valor cultural de unas u otras ${ }^{4}$. Es la relativa novedad de tal giro la que apunta a la necesidad de tomar con prudencia la apresurada explicación de este como una hegemonía de lo visible, que triunfa - para algunos con efectos catastróficos- sobre las culturas de la lectoescritura. En el juego de jerarquías entre los distintos sentidos, todos quedarían subsumidos bajo el dominio de la visión que reordena la economía de atención y el sistema somatosensorial al completo, lo cual además reproduce el viejo debate entre alta cultura y cultura de masas, en el que hoy los defensores de la primera tendrían todas las de perder. Sin embargo, privilegiar la mirada y las imágenes no es un rasgo único de las sociedades contemporáneas, como tampoco lo es de las sociedades occidentales. Al limitarse a subrayar la hegemonía de la visión en la cultura contemporánea se olvidan con demasiada facilidad la diferencia histórica y cultural. Se corre el riesgo además de reducir la crítica política a la crítica iconoclasta, entendiendo la destrucción de imágenes como la única forma efectiva de desvelar la realidad que su poder y omnipresencia obturan. ${ }^{5} \mathrm{~A}$ continuación analizaré algunas de las líneas de fuerza generadas en torno a las con-

\footnotetext{
3 Brea, J.L., Las tres eras de la imagen, Madrid, Akal, 2010, p. 72.

4 Mitchell, W.J.T., « Mostrando el Ver: Una crítica de la Cultura Visual», Estudios Visuales, 1 (2003), pp. 17-40.

5 Por otro lado, queda fuera de foco la interesante cuestión de cómo es una cultura visual en una cultura en la que la visión no se considere o proclame soberana. En este punto Mitchell acudía a una conocida ficción novelística, El ensayo sobre la ceguera de José Saramago, Ibídem, p. 32. Pero se pueden aportar también ejemplos etnográficos como el de los Kaluli de Nueva Guinea, cultura situada en un entorno vegetal frondoso y con luz escasa, dentro de la que es preeminente lo auditivo -la dialéctica entre ruido, música, silencio- y por tanto es "hegemónico" el sentido del oído. Feld, S., Sound and Sentiment: Birds, Weeping, Poetics and Song in Kaluli Expression, Pennsylvania, University of Pennsylvania Press, 1990.
} 
diciones contemporáneas de la imagen y la visualidad. En primer lugar repasaré el problema de asociar el giro visual contemporáneo a algún tipo de esencia visual, entendiendo desde aquí que la centralidad de las imágenes en el mundo contemporáneo significa que la visualidad contemporánea puede entenderse como escindida del lenguaje, los textos y otros medios. Se trata, al contrario, de entender las formas específicas en que las imágenes y la visualidad contemporánea se articulan, dialogan y friccionan con aquellos. Que en el mundo contemporáneo las imágenes tomen una relevancia quizás inédita no quiere decir que éste pueda ser entendido como esencialmente visual. En un segundo momento, insistiré en matizar la supuesta novedad del giro visual y de la propia idea de giro entendiéndolo más en los términos de una reorientación de conceptos, prácticas y perspectivas que como un simple corte o cambio de paradigma. El giro visual debe entenderse en diálogo y debate con respecto a otros giros que no se suceden sino que más bien se entrelazan de formas complejas, como el material, a través de lo cual se reposicionan conceptos como el de representación, presencia y agencia, el giro performativo, a través del que se puede abordar el poder constitutivo de lo visual en las sociedades contemporáneas, o el afectivo, por el que se pueden replantear las relaciones entre imagen, representación y corporalidad. De ello se deriva la necesidad de abordar estos giros como oportunidad para cuestionar las separaciones modernas entre objetos, imágenes y humanos y las múltiples mediaciones de la experiencia visual. A partir de aquí se propone examinar la problemática cuestión de la materialidad de la imagen contemporánea, en la medida en que ésta se postula a menudo como elemento y ejemplo clave de los procesos de desmaterialización y virtualización contemporánea, dentro de los que a menudo se tiende a identificar apresuradamente el antihumanismo con el antimaterialismo. Finalmente profundizaré en esta cuestión de la materialidad de la imagen retomando el análisis de las relaciones entre imágenes y lenguaje para encontrar en la visualidad contemporánea una articulación entre materialidad y exceso figural que problematiza y contamina los encuentros entre imágenes, palabras y escritura, redefiniendo las condiciones de la representación y la historización de lo visual.

\section{La visualidad impura}

Desde luego es posible localizar la lucha entre palabra e imagen que perfila el escenario dentro del que se proclama el dominio actual de la imagen, ubicándola por ejemplo en algún punto de la modernidad o la posmodernidad occidental. También lo es volver a la idea de una disputa entre distintos regímenes del valor cultural, ligados aquí a regímenes de la percepción, por la que los signos lingüísticos, textuales, se toman como arbitrarios, convencionales, y por tanto abiertos a dar voz 
a una infinidad de producciones e interpretaciones culturales. Por su parte, las imágenes se entienden como transparentes, ajustadas al acto fisiológico de ver, y por tanto asociadas a lógicas de presencia e inmediatez que dejan poco margen para la apropiación crítica, si no es que conducen directamente a la manipulación y el sostenimiento de los imperativos del poder. El laberinto, una imagen recurrente en el arte y la literatura modernista, puede referirse al laberinto del oído, oponiéndose a la figura de la pirámide que, con sus connotaciones de solidez, distanciamiento y mirada elevada, a su vez remite también al cono de visión y a la perspectiva lineal6. Sin embargo, es precisamente esa separación la que queda trastocada en el giro visual contemporáneo, en la medida en que la supuesta victoria de las imágenes no puede entenderse sin atender a su naturaleza construida, sus complicidades con el poder, su falta de evidencia inmediata. Ha llegado a ser evidente que nada relacionado con las imágenes y la visión es evidente. De ahí que exista un desplazamiento de la visión a la visualidad el cual, según Mieke Bal, es aquello que hace de la visión un lenguaje y en consecuencia desliga a la visualidad de cualquier idea de esencia visual7. Y no se trata de reducir la primera a lo segundo sino de introducir en el debate la noción de la impureza visual, que posibilita explorar los encuentros $\mathrm{y}$ desencuentros entre palabras e imágenes de forma productiva y comprometida con una interdisciplinariedad con filo crítico. Esto tampoco significa descartar de principio, a través del subrayado de la naturaleza construida de las imágenes y de los actos de ver, las dimensiones no culturales de estas actividades culturales que aquellas enmarcan y condicionan, y que no pueden quedar sepultadas bajo la fuerza de los modelos de construcción social y lingüística. Si hablamos de cultura visual han de quedar implicados ambos términos en su negatividad, reencontrados en la fricción de dos negatividades. El término visual es impuro, sinéstesico y pragmático, y el de cultura es diferencial, variable, emergente en el encuentro entre diferencias, resistencias e imposiciones ${ }^{8}$.

Acudamos por un momento al concepto de alfabetización visual ${ }^{9}$. La alfabetización visual recoge la idea de que las imágenes son leídas y que el significado puede ser comunicado a través de la lectura, y así, se refiere a la capacidad para entender, interpretar y compartir mensajes visuales. Pero esta es una afirmación que solo se acerca parcialmente al propósito de una aproximación crítica a lo visual acorde con lo ya expresado. Ciertamente se da un paso significativo cuando las imá-

\footnotetext{
6 Jay. M., Downcast Eyes. The Denigration of Vision in Twentieth-Century French Thought, Berkeley, Los Angeles, University of California Press, 1993, p. 229.

7 Bal. M., «El esencialismo visual y el objeto de los estudios visuales», Estudios Visuales, 2 (2004), p. 25.

8 Ibidem, p. 33.

${ }_{9}$ Una revisión profunda de este concepto se encuentra en Elkins, J., (ed.), Visual Literacy, Nueva York, Routledge, 2008.
} 
genes son consideradas como textos, ya que se introduce la idea de que poseen y producen significados y que demandan un esfuerzo analítico de lectura- y por tanto existe una dimensión de ilegibilidad en las imágenes-. Los motivos, colores, manchas, líneas, puntos, tratamientos de la luz y las texturas, producen significado y por tanto forma y significado no pueden quedar separados. Como los textos, las imágenes no generan significado de forma inmediata, no son trasparentes, son medios y mediaciones inscritos en un determinado orden representativo, que deben ser abordadas a través de la lectura. Pero la imagen no es algo que se pueda reducir al lenguaje por analogía, ni mucho menos es la mera ilustración de un texto. Se desliza en dicha analogía la pretensión de ubicar al texto o al lenguaje como elementos clave de un metalenguaje de la representación. No obstante, si se quiere mantener la tensión crítica ha de reconocerse tal metalenguaje como formado a su vez por una "serie de figuras e imágenes que en sí mismas deben ser analizadas"10. El de texto es entonces un concepto que sostiene, y no concilia, la tensión entre imagen y lenguaje. $\mathrm{Y}$ es este momento controvertido de los conceptos el que resulta más productivo ${ }^{11}$. Si la imagen no puede quedar subsumida al lenguaje, se encuentra no obstante en él la vía para oponerse a la lógica del significado autoevidente de lo visual que lo deja blindado frente al análisis. Y si hay una dimensión textual o lingüística en la visión, del mismo modo existe una visual en los actos de lectura. La visualidad no es solo una propiedad característica de los objetos, se encuentra también asociada a los actos de visión relacionados con esos objetos: incluso los textos literarios elaboran mezclas sensoriales y afectivas que entretejen actos de lectura y percepción ${ }^{12}$.

\section{Giros sobre giros}

Con todo, el giro visual en torno al que se han ido componiendo los Estudios Visuales ha derivado en lo que Keith Moxey llama una cierta desconfianza posderridaniana con los poderes del lenguaje, relanzando el interés en diversos ámbitos del análisis cultural por el poder de los objetos, sus formas de agencia o sus lenguas propias ${ }^{13}$. No se llega muy lejos si se entiende esta tendencia como una especie de rectificación a las derivas hacia la virtualización del mundo contemporáneo, a la que se opondría un retorno de la materialidad, incluida la de la imagen, como signo que a través del significante da presencia sensible y cuerpo al significado. En este esfuerzo queda sin atenderse lo que Mitchell reconocía como otro de los mitos en

\footnotetext{
10 Mitchell, W.J.T., Teoría de la Imagen, Madrid, Akal, 2009, p. 22.

${ }_{11}$ Bal, M., Conceptos Viajeros en Humanidades, Murcia, Cendeac, 2009, pp. 40-41.

12 Bal 2004, op. cit. (nota 5).

13 Moxey, K., «Los Estudios Visuales y el giro icónico», Estudios Visuales, 6 (2008), pp. 8-23.
} 
torno a la cultura visual. En esta ocasión se trata de la idea de que esta supone una predilección por la imagen desmaterializada e incorpórea. A ello Mitchell respondía con el recordatorio de que la imagen desmaterializada y el artefacto corporeizado son elementos constantes dentro de la dialéctica de la cultura visual. Las imágenes actúan dialécticamente en relación a sus variadas concreciones materiales representativas ${ }^{14}$. Daniel Miller anota que las relaciones entre materialidad e inmaterialidad no están más claras en los dominios seculares que en los religiosos ${ }^{15}$. Y en una línea parecida, Fernando Broncano ha observado que la misma experiencia de lo inmaterial es una experiencia mediada por artefactos materiales ${ }^{16}$.

La insistencia en entender la imagen como presencia e inmediatez, linealmente opuesta a una supuesta deriva hacia la virtualización y la disolución de la experiencia material y corpórea, podría, según Janet Wolff, estar desgastando la potencia crítica de las distintas modalidades de análisis de la imagen y de la visualidad ${ }^{17}$. El poder de las imágenes, ubicado en las cercanías de la noción de presencia, queda así desanclado de las determinaciones y dependencias sociales, culturales e históricas que lo modelan. El subrayado de la presencia estaría trabajando en contra de las inquietudes que han ido componiendo tentativamente y de forma general el campo de los estudios visuales. Si estos se implican en el reconocimiento de la importancia de las imágenes y los imaginarios en las sociedades actuales, como portadores y generadores de valor cultural y simbólico, se enuncia en efecto una objeción a los estudios humanísticos, tradicionalmente volcados en el estudio de las letras, es decir, dando privilegio a la relevancia del lenguaje-como parte de la herencia logocéntrica- en la configuración del conocimiento y en los procesos de creación de significado. Pero la cuestión es si el desplazamiento de ese logocentrismo conduce necesariamente a desalojar al lenguaje del análisis y, como cabría esperar, girarlo hacia una noción de presencia- que como se ha señalado gravita en torno a otras, como la inmediatez, el poder de las imágenes o la capacidad de agencia de los objetos- en la que se considera que se agota el significado, permaneciendo este en alguna medida inabordable, ubicado en la esfera fenomenológica de la materia muda, del cuerpo, de las experiencias inexpresables.

Si de lo que aquí se trata es, en términos generales, de un giro material en las Humanidades y de entender cómo este se cruza con el giro visual sería recomendable detenerse a analizar la propia idea de giro, tan recurrente en las últimas décadas. El giro es un recurso para reconocer nuevas orientaciones según las que los saberes

\footnotetext{
14 Mitchell 2003, op. cit. (nota 2), p. 25.

15 Miller, D., (ed.) Stuff, Cambridge, Polity Press, 2010, p. 74.

16 Broncano F., La estrategia del simbionte. Cultura material para nuevas humanidades, Salamanca, Delirio, 2012, p. 70.

17 Wolf, J., «After Cultural Theory: The Power of Images, the Lure of Immediacy», Journal of Visual Culture, 3,11 (2012), pp. 3-19.
} 
se redefinen internamente y se cruzan con otros. Hasta dónde llegan estos desplazamientos depende del reconocimiento de que esos giros son, en realidad, figuras narrativas a las que se ha acudido a lo largo del tiempo para explicar reconfiguraciones heterogéneas de las epistemologías, las sensibilidades o las formas de socialización. Recuérdese en este punto que para explicar en este caso el giro lingüístico Richard Rorty, señaló que los cambios en el orden cultural no se producían en base a nuevos hechos o constataciones científicas, sino en base al surgimiento de nuevas descripciones del mundo, cambios de léxico que perfilan nuevos conceptos y realidades 18 .

En cualquier caso, en lo que toca al giro material se parte de la insuficiencia del impulso posmoderno a la hora de deshacer los binarismos heredados de la modernidad, en la medida en que tal critica muestra todavía demasiadas dependencias con los órdenes epistémicos heredados. El giro material entiende que la separación mente y cuerpo en las Humanidades es una de esas opciones fosilizadas -en el sentido de lo que Ulrich Beck llamaba conceptos zombies-, que, con todo, siguen ejerciendo fuerza impositiva y regulatoria. El privilegio de la cultura sobre la naturaleza, de las palabras sobre las cosas, es parte de esas divisiones que mantienen implícitamente jerarquías dualistas. Para rearmar el impulso hacia su disolución se han emprendido una serie de giros que, como el mecanismo de ruedas de un reloj, se articulan entre sí apuntando a un cambio de paradigma en unas Humanidades renovadas dentro de las que se inscriban con todas las consecuencias el cuerpo, la naturaleza, la materia, los artefactos y las cosas. El giro performativo vuelve a llamar la atención sobre un proceso de creación en el que el producto final, si lo hay, es en todo caso una fase o una parte, no necesariamente la más importante, de aquel, en el que además el discurso de la autoría individual suele quedar diluido en lo colectivo. El giro afectivo se compromete con la cuestión de la corporalidad, y las dimensiones sensitivas de la experiencia de espectadores y usuarios. Y podría decirse que el giro material, al poner el foco sobre los problemas de la agencia humana y no humana, las relaciones entre humanos y no humanos, entre objetos naturales y objetos no nacidos, comprende a los anteriores giros enunciando una pregunta por la materia, elaborada dentro de los paradigmas de lo que ha venido en llamarse un nuevo materialismo.

No obstante, cuando este giro material se perfila como una llamada a la recuperación de alternativas filosóficas materialistas en las ciencias sociales que se opondrían al idealismo al que al parecer conduce inevitablemente la insistencia en el texto y el lenguaje, se pierde la complejidad de los procesos materiales, que no pueden reducirse a una noción estrecha de materialidad. Desde luego es el enfoque materialista el que permite reintroducir en el análisis cultural las cuestiones desconectadas de la localidad, los cuerpos, la economía, la desigualdad o la infraestruc-

18 Rortry, R., El giro lingüístico, Barcelona, Paidós, 1989. 
tura. Pero si quedan sin cuestionar los conceptos de materia y de materialidad, estos a su vez permanecen desligados de procesos especulativos, ecológicos, temporales, espaciales y visuales cuyas dimensiones y alcance quedan fuera de las promesas ligadas a una definición reduccionista de la materia ${ }^{19}$. En realidad, tomar partido por la materia frente a la cultura o el lenguaje mantiene intacta la forma de división binaria que Bruno Latour define como purificación. Un compromiso con la materialidad que la ubica en oposición a la cultura, quizás en nombre de la objetualidad, no alcanza a poner en cuestión la división entre ambas. Para Latour el problema de la materialidad vendría más bien a reemplazar esa división separadora de ambos tér$\operatorname{minos}^{20}$. Esta separación, ejercida por ejemplo a la hora de atribuir a los objetos capacidades de agencia humana significa insistir en una separación imposible entre sujetos y objetos, humanos y no humanos ${ }^{21}$. Cualquier discusión sobre la materialidad que empieza y acaba con el objeto está condenada, advierte Christopher Pinney, a fallar, ya que componer la materialidad como objetualidad privilegia uno de los extremos de esa lógica binaria, reforzando al otro al que trata de contestar 22 . Hay aquí una diferencia significativa entre la propuesta de reconocer que las cosas toman una vida social y un cariz biográfico a través de su paso por la vida de la gente $^{23}$ y la proclamación de que la distinción entre gente y cosas, entre humanos y no humanos, debe ser superada. Del mismo modo que no es lo mismo señalar que la gente y las cosas emergen dialécticamente en sus encuentros ${ }^{24}$ y afirmar que en determinados contextos gentes y cosas son idénticas 25 . Es pertinente recordar, como muestra la experiencia etnográfica, el hecho de que en determinadas situaciones la gente habla o actúa con las cosas de formas que contradicen las asunciones (occidentales) de lo que debería ser una cosa. La propia noción de cosa es compleja y debería dialogar con las de objeto, artefacto o sustancia. El etnógrafo encuentra contextos culturales con repartos heterogéneos de lo visible y lo invisible, lo exhibible o lo usable. Marilyn Strathern señala que es precipitado entender que las culturas de

\footnotetext{
19 Rose, G., Tollia-Kelly, D.P. (ed.), Visualiy/Materiality: Images, Objects, and Practices. Burlington, VT, Ashgate, 2012, p. 2. Tim Ingold añade al debate de los Estudios de Cultura Material la distinción entre materiales y materialidad. Véase Ingold, T., «Materials against materiality», Archeological Dialogues, 14, 1, (2007), pp. 1-16.

20 Latour, B., Nunca hemos sido modernos. Ensayo de antropología simétrica, Madrid, Debate, 1993.

21 Por ejemplo en Gell, A., Art and Agency: An Anthropological Theory, Clarendon Press, Oxford, 1998.

22 Pinney, Ch., «Things Happen: Or from which moment does that object come?», en Miller, D., (ed.) Materiality, Durham, Duke University Press, 2005, pp. 256-272.

23 Appadurai, A., The Social Life of Things. Commodities in Cultural Perspective, Cambridge, Cambridge University Press, 1988.

24 Miller 2005, op. cit. (nota 20).

25 Strathern, M., Property, Substance, and Effect: Anthropological Essays on Persons and Things, Londres, Athlone Press, 1999. Y Holbraad, M, «Can the Thing Speak?», OAC Press. Working Papers Series, 7 (2011), p. 4.
} 
Nueva Guinea traten a individuos, determinados artefactos y animales en primer lugar como objetos, a partir de la observación de que en la práctica estos son tomados como cosas, resultado de algún proceso de reificación. Es más bien al revés, son objetos -objetivaciones significativas que puntúan la vida social-porque antes han sido tomados como cosas. La noción de cosa aquí se compone a partir del reconocimiento de su capacidad para crear relaciones como las que se dan entre sujetos, y así los objetos pueden ser comprendidos como personas ${ }^{26}$. A través de unos $u$ otros procesos de personificación -que ya no es posible descartar etnocéntricamente como simples recaídas en el fetichismo o la superstición- aprendemos que las cosas, los materiales, los objetos y los artefactos, modelan y participan las relaciones entre personas y que no son recipientes pasivos de la acción humana. Los procesos de objetivación moderna en los que el objeto se opone al sujeto del conocimiento- el Gegenstand heideggeriano- toman a aquellos en consecuencia como la conversión de las cosas en objetos a través de la teoría (la ciencia) y de la praxis (el trabajo). Pero también son procesos de objetivación que no se ajustan a tal razonamiento el intercambio de dones, las formas de exhibición de imágenes, cuerpos o artefactos, las dramatizaciones o la puesta en común de un discurso, la exposición de una ofrenda o de un conocimiento. Estas y otras prácticas, desplazadas sobre el eje de las diferencias culturales, del cambio social y tecnológico, se presentan como modos heterogéneos de objetivación con potenciales específicos de reflexividad, apropiación e interpretación. Forman parte de ideologías semióticas con repertorios de posibles realizaciones prácticas dentro determinadas economías de la representación 27.

Aquellas entidades que las separaciones de la modernidad definen como gentes y cosas han de entenderse ahora como híbridos anudados en procesos simétricos y complejos de transformación mutua 28 . De este modo la agencia no es la actualización de una intención humana, es una propiedad emergente de una red de relaciones híbridas. Aparecen así nuevas entidades analíticas: el ensamblaje híbrido de humanos y no humanos que solo gana consistencia por su capacidad de actuar como tal dentro de relaciones transformativas ${ }^{29}$. Dentro de las esferas de lo político, de la

\footnotetext{
26 Strathern 1999, op. cit. (nota 23).

27 Keane, W., «Semiotics and the social analysis of material things», Language \& Communication, 23 (2003), pp. 409-425.

28 Pero conviene apuntar que es precisamente esa hibridación la que, según advierte Ingold, puede diluir la especificidad de los materiales y por tanto desdibujar el objeto de estudio propio de los Estudios de Cultura Material. Ingold 2007, op. cit. (nota 17).

29 Aquí se articula incluso la filosofía política con una ecología -que no tiene que ver con las dependencias fijas entre especies y ecosistemas- dentro de la que, por ejemplo Jane Bennett, propone prestar atención al hecho de que en los debates públicos la gente, los humanos, no son los únicos actores significantes. Bennet, J., Vibrant Matter: A Political Ecology of Things, Durham, Duke University Press, 2010.
} 
producción de conocimiento, socialización y afectividad se multiplican las circunstancias y las áreas en las que los individuos se relacionan con ciertos objetos no solamente como medios o instrumentos para la acción y el pensamiento, sino como seres que experimentan, sienten, reflexionan, recuerdan, interactúan o muestran agencia ${ }^{30}$.

\section{Cuerpos y objetos en el nuevo paradigma estético}

Ahora bien, esto tampoco debe hacer olvidar, más allá de algún apresurado descarte de lo corporal, que la centralidad del cuerpo y su ética, al sobredeterminar una subjetividad autoafirmativa que se postula como autónoma y supuestamente resistente -por ejemplo, y sobre todo, desde la esfera del consumo- a los ejercicios del poder, diluye los cruces de aquella con las desigualdades de clase, el Estado, o los modos de producción. No es necesario ir muy lejos para entender la importancia de atender a estos entrecruces. Basta con recordar cómo Felix Guattari, advertía que el neoliberalismo actual se caracterizaba especialmente por ajustar las esferas de la economía, la cultura y la producción de subjetividad, lo cual debería impulsar el análisis más allá de cualquier forma de determinismo económico, pero también más acá de la construcción de alguna subjetividad soberana capaz de imaginarse sobrevolando aquella alianza. Por otro lado, cabe aquí también destacar que la tradición materialista clásica- pongamos a Spinoza y Marx- no conduce necesariamente a la escisión de la ética y la moral respecto a la vida material, sino más bien a la problematización del cruce entre aquellas y la estética en su sentido de aesthesis, es decir, el estudio de las relaciones entre cuerpo, sensibilidad y mundo ${ }^{31}$. Es en tal cruce donde es posible imaginar otros órdenes sensibles y políticos comprometidos con la crítica a los modos de creación de valor dominantes, a través del encuentro entre modos de producción, de consumo, afectividad, práctica y discursividad. Lo que Guattari llama nuevo paradigma estético parte precisamente de la elaboración de la producción de subjetividad como motor de aquel, incluyendo el papel activo de los universos de valor, la función de las enunciaciones colectivas, así como objetos y cosas que considera que son funciones pragmáticas de la existencia. Guattari propone plegar mutuamente las fuerzas materiales e inmateriales reconociendo en cada una de ellas un cierto margen autonomía y a la vez su tramado relacional con otras fuerzas ${ }^{32}$.

30 Knorr Cetina. K., Brugger, U., «The Market as an Object of Attachment: Exploring Postsocial Relations in Financial Markets», Canadian Journal of Sociology, 25, 1 (2000), pp. 141-168.

31 Videl Gamonal, J., «La imagen de las cosas: Cuerpo y objeto ante la crisis del consumo», en Fernández Polanco, A. (ed.) Pensar la Imagen/Pensar con las Imágenes, Delirio, Salamanca, 2014, pp. 53-89.

32 Brunner, Ch., Nigro, R., Baunig, G., «Hacia un Nuevo paradigma estético. Ético-estética y la estética de la existencia en Foucault y Guattari», RADAR, MUSAC, 1 (2012), pp. 40-48. 
Los procesos de desmaterialización contemporáneos suponen más bien un desplazamiento de los cuerpos explotados a la periferia económica global, lo que significa que aquellos se implementan menos en la esfera de la producción que en las del consumo y la circulación de las mercancías, que por ello no pueden ser identificadas directamente como espacios autónomos para la contestación y la reapropiación critica. Esto nos lleva de vuelta a la cuestión marxiana de la transformación fetichista de las relaciones de trabajo en relaciones sociales entre objetos que invisibilizan las primeras. Pero en la modernidad los procesos de cosificación que convierten las cosas en mercancía -movimiento al que Marx quiere contraponer el esfuerzo de rencontrar el objeto atrapado bajo la forma mercancía- emergen sobre el fondo general de la fetichización de la historia como progreso. Estas narrativas, al no reconocer su propia dimensión fetichista, la proyectaron sobre la denigración de aquellos objetos e imágenes, cuerpos y culturas, que no supieran orientarse hacia la resolución teleológica que aquellas prometían. Todo lo desviado de la dirección correcta del transcurrir histórico quedó así apartado como regresión a un estado precivilizado, refractario a las promesas del progreso histórico (y a las exigencias paralelas de normalización, adaptabilidad y estandarización generalizadas).

Con la identificación de lo no ajustado a la lógica del progreso como fetiche desviado, se paraliza la reflexión acerca de las dependencias con la cosificación general sobre la que aquella se sostiene. El discurso del fetichismo podría entenderse como un dispositivo de sujeción a través del cual se logra ubicar, en negativo, a todas esas imágenes falsas desviadas de la linealidad progresiva, no por ser "malas copias" sino por contener algo "que, de ser puesto en libertad, destruiría la jerarquía presupuesta del original y la copia, algo que arruinaría las relaciones establecidas entre lo semejante (verosímil) y lo desemejante (fantástico)"33. La historia de la migración semántica del fetichismo, según la denominación de Giorgio Agamben, así como la de sus usos, es compleja. El término fetiche pasa desde el espacio minorizado de las culturas "no civilizadas"- construido sobre todo por el discurso de la ciencia antropológica decimonónica- a la teoría económica de la producción en masa de mercancías y, en paralelo a ello, alcanza a la vida sexual como perversión. El reconocimiento de un objeto como fetiche señala "una transgresión de la regla que asigna a cada cosa su uso apropiado" 34 . Es así posible entrever el sistema de reglas, el régimen de valor, por el que se determinan las normas de uso adecuadas para objetos y acciones. Quedan insinuadas, como interrogación para la genealogía de la dominación, las formas de atribución dogmática y represiva de las normas del

\footnotetext{
33 Pardo, J. L., Esto no es música. Introducción al malestar en la cultura de masas, Barcelona, Círculo de Lectores, 2007, p. 335.

34 Agamben, G., Estancias. La palabra y el fantasma en la cultura occidental, Valencia, Pre-textos, 1995, p. 108.
} 
uso apropiado, virtuoso, de las cosas, las acciones y los cuerpos ${ }^{35}$. Hay un aliento de disenso, utópico incluso, en el cuestionamiento de ese reparto de tareas y representaciones, abierto de forma ambigua a otras formas del sentir y del obrar ${ }^{36}$. En el límite de la reificación completa de la vida, de la alienación de la capacidad de cambio como retorno regulado de lo mismo en lo novedoso, parece destellar un desajuste- el que señala el encuentro de los anhelos secularizados de emancipación con su endurecimiento normativo y represivo- que sirvió por ejemplo a Benjamin para entender la sensibilidad contemporánea de las cosas en cuanto sedes del deseo, la afectividad y la posesión. 37

Y aquí reaparece el problema de la imagen, porque en la crítica del fetichismo de la mercancía, Marx entiende que el problema del valor en el capitalismo tiene que ver con un exceso ligado a la lógica de las imágenes animadas 38 . La transformación de las producciones humanas en imágenes capaces de establecer relaciones con los seres humanos, de reproducirse en los trayectos de asignación de las finalidades y los usos, indica que es imposible resolver la cuestión del valor según los criterios del utilitarismo o de la cuantificación del tiempo de trabajo. El exceso de valor adherido a las imágenes en el proceso de mercantilización reserva para ellas un cometido central en la reproducción de la ideología dominante. Pero, según Mitchell, es erróneo caracterizar a Marx como un simple enemigo de las imágenes, un iconoclasta que pretendiera depurar de imágenes a la sociedad para reorientarla sobre el horizonte emancipatorio de superación de la falsedad. Es, señala Mitchell, el orden social el que ha de ser cambiado, no las imágenes. Marx entiende que las imágenes deben ser entendidas, no destruidas ${ }^{39}$.

Desde un enfoque semejante, incluso si tomamos la cultura visual contemporánea como una intensificación lineal de la transformación del mundo en imagen,

35 Piénsese en la identificación entre el don y la mercancía con dos tipos de sociedad, que sólo es posible si se esencializan los términos de tal identificación. Es una separación que deja al margen las relaciones desiguales de dominio colonial entre aquellas. Frow, J., Time and Commodity Culture, Oxford, Oxford University Press, 1997, p. 125.

36 Por ejemplo, desde la perspectiva del fetichismo de la mercancía y del psicoanálisis Luce Irigaray se cuestiona la posesión masculina del deseo y del derecho a la poligamia y la idea de la "escasez de mujeres", para sugerir otra economía política, la posibilidad de confundir productivamente el uso y el intercambio y la consecución de una subjetividad femenina autónoma. Irigaray, L., Ese sexo que no es uno, Madrid, Akal, 2009, pp. 127-147.

37 Se trata también de la declinación del fetichismo de la mercancía sobre el del objeto parcial y de la movilización de la vida afectiva en referencia a las cosas. El fetichismo se abriría a una dimensión productiva insinuada en la misma desviación que provoca la imposibilidad de una representación acabada, y su consiguiente sustitución por un objeto parcial. Véase Hernández-Navarro, M. Á., «Retóricas de la obsolescencia. El arte contemporáneo y el retorno de lo material», Revista de Occidente, 357 (2011), pp. 27-47.

38 Mitchell,W.J.T., What do pictures want? The lives and loves of images, Chicago, Chicago University Pres, 2005, p. 94.

39 Ibidem, pp. 94-95. 
quedan en entredicho aquellas aproximaciones que dicen que la crítica a las imágenes consiste en desvelar aquella realidad, digamos material, que aquellas ocultan. El espectáculo, señalaba Guy Debord, sitúa a la imagen en el centro de las mediaciones sociales, desplazando lo que antes era directamente vivido al escenario de la representación. Pero apreciaciones de este tipo fallan al reconocer la especificidad del régimen escópico contemporáneo, o, como dice Kaja Silverman "lo históricamente variable en el campo de visión" 40 . Se trata entonces menos de evocar algún momento de inmediatez perdida que de entender los términos específicos de la mediación, también en sus dimensiones materiales. El mundo devenido imagen resulta del proceso de fetichización generalizada llevado a un grado extremo de saturación. Las imágenes dejan de ser mediadoras del sistema de los objetos y representantes de su régimen de valor para pasar a ganar capacidad de agencia, que permitiría a las imágenes ser mediadoras de sí mismas, "productos negociados por su mediación"41. Tal sería, pues, el panorama contemporáneo de la vida de las imágenes: uno en el que los trayectos del deseo no se detendrían sobre los objetos clausurando el proceso de mercantilización. Ni el deseo ni el sentido son distinguibles de esos mismos trayectos, de ese tráfico cultural.

\section{Mediadoras de sí mismas}

El análisis de la imagen, como parte del análisis cultural de las prácticas de producción de significado, no se reconocerá entonces en el juego de dualismos que separa a sujeto y objeto, mente y cuerpo, materialidad e inmaterialidad, apariencia y esencia. Jacques Rancière señala que tal lógica resurge en la distinción, más o menos explícita, entre imágenes y visibilidades ${ }^{42}$. Si estas últimas, en cuanto que ligadas a una visualidad indeterminada, sólo serían capaces de remitirse a sí mismas- habitando un régimen del simulacro-, aquellas aún mantendrían una referencia trascendente, lo que les permitiría sostener una relación con la Verdad, con un otro más allá de sí mismas. Lo visible queda asimilado al ámbito de lo aparente y lo doxático, propio del "pueblo" y de un régimen de "no-verdad". En contra de estas aproximaciones es necesaria una teoría de la imagen entendida como pregunta por las formas de distribución de lo visible y lo decible, no sujeta a obligaciones trans-

\footnotetext{
40 Lo específico de nuestra época, señala esta teórica, no es tanto la fundación espectacular de la subjetividad y del mundo como los términos en los que se construye esa fundación. Es decir, la lógica de las imágenes a través de las que figuramos objetos y nos figuramos, y el valor conferido a esas imágenes como pertenecientes a la organización del campo visual. Silverman, K., El umbral del mundo visible, Madrid, Akal, 2009, p. 203.

41 Brea 2010, op. cit. (nota 3), p.72.

42 Rancière, J., Le destin des images, París, La Fabrique, 2003.
} 
cendentales. La imagen no necesitaría una redención, por así decir, teológica, sino, de nuevo, ser reubicada en el cruce de lo estético y lo político. Se trataría menos de explorar la relación entre imagen y verdad que de armar la crítica para abordar la elaboración del sentido según la dialéctica inmanente entre imagen y palabra. Las imágenes generan significado en su articulación con lo cotidiano, con el espacio social, con el sistema de los objetos, ámbitos mundanos donde comparecen transitoriamente usos no reglados, insinuaciones de lo posible, tentativas e inminencias equívocas. La vida social de las cosas, las imágenes y los sujetos, ya no se reconoce en una economía de la representación erigida en torno al dualismo de lo falso y lo verdadero, de la esencia y la apariencia, de lo real y lo virtual, sino en la problematización de esas relaciones bajo paradigmas complejos. Hay que preguntarse si no será más bien que, en la confusión entre lo real y la apariencia, es esta última la que sale perdiendo. La apariencia es una realidad construida, "esa realidad complementaria que hace que la realidad esté perdiendo el orden necesario de las cosas, que se vuelva problemática, abierta a la elección, al conflicto"43. Si lo que aquí queda rechazado es la apariencia, estaríamos entonces no en una sociedad del espectáculo que olvida la realidad, sino más bien en una "sociedad del cartel" que encadena a aquella a la tarea de sostener un único discurso, a legitimar un único régimen de la mirada, de los significados, de la sensibilidad. Liberar a las apariencias sería en consecuencia el propósito de una teoría y una práctica críticas de la imagen, atentas, no en último lugar, a sus nuevas modalidades de materialidad y presencia. El mundo-imagen es nuestro mundo global compartido y explorar otras modalidades del estar juntos, otras formas del disenso y de la crítica, no quiere decir "alcanzar lo que está bajo la superficie de la imagen, sino ampliarla, enriquecerla, darle definición, tiempo"44.

No sería la última tarea asociada a tal esfuerzo aquella que se implicara en comprometerse con la puesta en evidencia de los marcos previos en los que se ubica la imagen, una escenificación polémica de aquellos escenarios por los que la imagen se nos hace aceptable, presentable y, al cabo, inane. Estos se encuentran a menudo invisibilizados a través de su propia exhibición, dictaminándose así un régimen de obviedad que agota lo posible en un real no mediado. El consenso impuesto resulta cuestionado en la tensión entre la interpretación de la forma visual como medio y como agente, es decir, tanto como instrumento "para la manipulación y (...) como una fuente aparentemente autónoma y capaz de decidir sus propios objetivos y significados, y el modo en que éstos son trasmitidos al otro" 45 . Alrededor de este conflicto las imágenes definen una cultura visual como formas de conexión y transac-

43 Rancière, J., Momentos políticos, Buenos Aires, Capital Intelectual, 2011, pp. 56-57.

44 Buck-Morss, S., «Estudios Visuales e imaginación global», en Brea, J.L. (ed.) Estudios visuales. La epistemología de la visualidad en la era de la globalización, Madrid, Akal, 2005, p. 159.

45 Mitchell 2003, op.cit. (nota 2), p. 34. 
ción social, comprometidas en el modelado de las zonas de contacto y los términos de la mediación, de las pantallas, los interfaces y los imaginarios, que configuran el entramado de los encuentros con la alteridad y la diversidad:

En tanto que enlaces o entidades subalternas, las imágenes actúan como filtros a través de los cuales reconocemos y, por supuesto, confundimos a los otros. Suponen mediaciones que, paradójicamente, hacen posible lo 'no-mediado' y el 'enfrentamiento' a todas aquellas relaciones que Raymond Williams postula como el origen de la sociedad como $\mathrm{tal}^{46}$.

El exceso de imágenes significa hoy la crisis de los anhelos que entendían a la imagen como depositaria de un trazo de verdad, por débil que éste fuera. El agotamiento de la representación marca la vida contemporánea de las imágenes en dos sentidos contrapuestos entre lo real dado y lo posible elaborable. Por un lado, la disolución de las capacidades de mediación polémica de la imagen en el ámbito sobresaturado de la comunicación. Por otro, el hecho de que las imágenes pasan a ser mediadoras de sí mismas, desmantelando así la economía del parecido mimético donde tradicionalmente encontraron su lugar. Es en este punto donde se puede profundizar en ese giro, cambio de paradigma o de régimen escópico. Que las imágenes son mediadoras de sí mismas no significa que el mundo de los objetos desparezca, sino que aquellas ya no están ancladas a su aparecer sustanciado en objeto; que, para ellas, las exigencias de ubicación e incrustación en el objeto son desplazadas hacia a una economía de productibilidad que tiene que ver más con las lógicas comunitarias e interpersonales de lo cognitivo- las imágenes pasarían a ser objetos de conocimiento- que con el principio de escasez característico del intercambio capitalista 47 . Desde este punto de vista, la cuestión de la materialidad de la imagen ya no se limita a su sedimentación en un soporte material al que convertiría en un objeto visual. Se proyectan sobre las formas y efectos de los procesos de mediación que componen las modalidades heterogéneas de objetivación que no necesariamente han de desembocar en la objetualización y la fetichización capitalistas, por ejemplo a través de los rituales cultuales que sigue instaurando la institución museística. En el participar de la imagen contemporánea, digital, electrónica, del trabajo inmaterial se perfila la ocasión de inventar relaciones con el mundo, relaciones materiales con las cosas, desajustadas respecto a los imperativos economicistas de la reproducción y la explotación social y cultural. La cuestión de la materialidad no debe quedar fuera de la esfera de producción de modos de vida, la exploración de formas de subjetividad individuales y colectivas.

\footnotetext{
46 Ibidem, p. 34

47 Brea 2010, op. cit. (nota 3), p. 93.
} 
Si las imágenes contemporáneas son mediadoras de sí mismas es en el ámbito de la mediación donde puede reformularse el problema de su materialidad, porque es a través de la identificación interesada entre desmaterialización e invisibilización de la mediación como las imágenes quedan cautivas al servicio de las formaciones de imaginario instituidas ${ }^{48}$. De hecho, si los Estudios Visuales, en la medida en que parten de una noción de visualidad que proyecta los actos de ver más allá del acto fisiológico de ver y atienden a cómo estos son impuros, atravesados por los otros sentidos, el lenguaje y el poder, se recomponen, según señalara Mark Poster, como unos Estudios de los Medios (Media Studies) que, a su vez - es nuestra hipótesisdeberían girarse hacia unos Estudios de los Medios como Mediaciones ${ }^{49}$. Es en el campo de los nuevos media donde se proclama más a menudo que en el mundo digital el cuerpo y la materialidad ya no tienen lugar. De acuerdo con Anna Munster ello reproduce una vez más el dualismo cartesiano entre mente y cuerpo ${ }^{50}$. La retórica habitual del mundo digital privilegia la mente sobre el cuerpo, de lo mental sobre lo físico. De este modo se desliza, según Munster, una noción de posthumanidad dentro de la que se define la crítica al humanismo como antimaterialismo. Esa superioridad de la máquina y el intelecto concede a la tecnología un lugar transcendental sobre el que se proyectan anhelos utópicos ligados a un perfeccionamiento, incluido en el ámbito biológico, de lo humano- paralelo al progreso tecnológicoque pasa por la superación de las pesadas obligaciones del cuerpo. En contra de esta aproximación Munster propone atender a las convergencias y divergencias, a los pliegues mutuos entre lo físico y lo tecnológico del mundo digital. La experiencia digital perfila una específica experiencia corporal y corporeizada al crear una compleja zona de mediación, un pliegue, entre lo real y lo virtual ${ }^{51}$.En esas zonas de límites fluidos entre la mirada humana y la mirada de los artefactos tecnológicos es donde se recompone y se redefine constantemente la cultura visual contemporánea. La de Munster es una teoría de lo digital de vocación barroca -su horizonte último

\footnotetext{
48 Brea, J. L., «Una imagen es una imagen: tres escenarios», en Jaua, M.V. (ed.) El cristal se venga. Textos, artículos e iluminaciones de José Luis Brea. México D.F., RM+Fundación Jumex, 2014, pp. $52-56$

49 Poster, M., «Visual Studies as Media Studies», Journal of Visual Culture, 1, (2002), pp. 47-55. Para (re)ensayar el paso hacia las mediaciones no sería la última referencia el clásico de Jesús Martín Barbero De los medios a las mediaciones, México, Gustavo Gili, 1987.

50 Munster, A., Materializing New Media: Embodiment in Information Aesthetics, Hanover, Dartmouth College, 2006.

51 Esa zona de contacto e intersección es entendida por Josep M. Català Domènech como una interfaz, a la que reconoce como la forma característica de la cultura visual y el sistema de representación actuales. La interfaz no es el soporte virtual y funcional sobre el que aparecen las imágenes, sino que las propias imágenes son interfaces activas (esta aproximación puede dialogar con la de las imágenes como mediadoras de sí mismas) que materializan el conocimiento y articulan la vida simbólica y los imaginarios contemporáneos. Català Domènech, J.M., La imagen interfaz. Representación audiovisual y conocimiento en la era de la complejidad, País Vasco, UPV, 2010.
} 
es la distinción imposible entre representación y realidad-, en la que resuenan una sobre otra la complejidad del objeto de estudio y del campo de investigación, con una metodología interpretativa y analítica que en consecuencia debe ser tan barroca como su objeto: expresamente transdisciplinar, capaz de dibujar trayectorias difractadas en su encuentro y fricción con los materiales, los códigos, los cuerpos, los signos, los sentidos o la economía.

La pregunta por la materialidad de la imagen contemporánea solo puede explorarse dentro de marcos semejantes. A partir de la caracterización de las relaciones entre lo material y lo virtual como barrocas, múltiplemente plegadas, se rescata esa dimensión alegórica de la imagen en la que lo escritural y lo figural entran en tensión. Christopher Pinney ha señalado que para estudiar la cuestión de la materialidad de la imagen, e incluso la más general de la cultura material, resultaría especialmente productivo retomar el concepto de figura en Lyotard52. Para el pensador francés la figura ejerce una presión sobre las clausuras filosófico-lingüísticas del discurso, señalando un ámbito radicalmente exterior a a aquellas. Frente a los límites de lo que puede ser reconocido, leído, identificado, dentro de un sistema lingüístico estable, la figura despliega un campo de intensidades afectivas, de sentidos no decodificables. Y en esta línea la materialidad podría ser definida, según Pinney, como un exceso figural que se resiste a ser contenido dentro de la clausura lingüística, declinando la inconciliabilidad de los juegos del lenguaje sobre su límite53. Pero no se trata aquí de entender ese exceso de la imagen como abundancia que se opone al orden de la escasez, mediante el gasto incontrolado o el dépense. Las imágenes ya no se mueven dentro de las lógicas de la falta y el exceso porque lo visual en su conjunto, en su prodigalidad y ubicuidad, ha pasado a habitar la esfera de lo cotidiano. El exceso figural viene a trastocar más bien la tendencia a sujetar la diferencia como signo, que ha de ser comprehendido por encima del objeto por un sujeto lingüístico que le concede su validez y significado, de forma que aquel queda vaciado, disponible, pasivizado. Se ejerce la traducción lineal de las cosas a signos, dejando fuera la corporalidad y la materialidad. Si es pertinente subrayar la dimensión material de los signos, en el mismo movimiento también debemos reconocer el carácter semiótico de la materia, sin la que permanecemos anclados en una aproximación representacional de los significados, perpetuando el dogma de que las palabras tienen el poder de representar las cosas como ya preexistentes 54 . Perder esta perspectiva impide, no en último lugar, entender, a través del exceso figural o de la materialidad, la imposibilidad de encajar a la imagen dentro de un contexto histórico y cultural por el que tanto aquella como este quedarían recíprocamente explicados. Las

\footnotetext{
52 Lyotard, J.L. Discurso, figura. Buenos Aires, La Cebra, 2014.

53 Pinney 2005, op. cit. (nota 20), pág. 269.

54 Barad, K., «Postmumanist Peformativity. Toward an Understanding of How Matter Comes to Matter», Signs: Women in Culture and Society, 28, 3 (2003), pp. 801-831.
} 
imágenes, subraya Pinney, están intensamente entramadas con la historia, pero no son solo un reflejo de algo que sucede más allá de ellas. Son parte de un dominio estético, material y figural que participa en la historia y la cultura, pero a la vez, existen en una temporalidad que no responde necesariamente a los mismos términos de las temporalidades políticas convencionales o las determinaciones historiográficas ${ }^{55}$. Por eso, con respecto a las imágenes, debemos historizar siempre, colocarlas en un contexto que es discurso, escritura, lenguaje y palabras. Pero al mismo tiempo es imperativo descontextualizar, anacronizar, porque las imágenes siempre se resisten al cierre textual, problematizan el contexto y la historia, marcando los límites de las explicaciones fundadas en estos términos al ser capaces de transcenderlos ${ }^{56}$. Es en ese desajuste donde la inmediatez que se atribuye a la imagen se muestra ella misma como una forma específica e interesada de mediación. La ambigüedad de la imagen emerge del cruce de dos incapacidades: la de agotar su significado en un contexto y la de que sus códigos solo aparecen como tales cuando se deja abrazar por el lenguaje. Pero lo que la imagen señala a la palabra en sus encuentros es que el mostrar se halla más allá del decir: existe una experiencia, un conocimiento, una revelación a través de la imagen -en este punto es pertinente invitar a un diálogo entre el exceso figural y el concepto de significancia en Barthes- que evidencia y desplaza los límites de lo que puede ser dicho. Porque de lo que se trata es de re-anudar las relaciones entre la visibilidad y la decibilidad, emplazándolas polémicamente en el corazón tecnocrático de un orden que insiste en agotar la realidad y lo posible en lo dado a ver.

\footnotetext{
55 Pinney 2005, op. cit. (nota 19).

56 Elkins, J., «Un seminario sobre teoría de la imagen», Estudios Visuales, 7 (2010), p. 153. El texto es la transcripción de un encuentro entre distintos estudiosos contemporáneos de la imagen. La dialéctica entre historización y anacronización es mencionada por W.J.T. Mitchell.
} 